\title{
Hornet predation on peacock butterflies and ecological aspects on the evolution of complex eyespots on butterfly wings
}

\author{
Christer Wiklund
}

Wiklund, C. 2005: Hornet predation on peacock butterflies and ecological aspects on the evolution of complex eyespots on butterfly wings. - Entomol. Fennica 16: 266-272.

Sixteen peacocks Inachis io (L.) and one red admiral Vanessa atalanta (L.) were killed by hornets Vespa crabro during a four day observation period in August 2002 on butterflies feeding on fermenting plums. Four successful attacks on peacocks were directly observed, and were invariably preceded by the butterfly opening its wings when attacked. When feeding, peacocks usually kept their wings closed and only flicked their wings open to prevent another approaching insect from alighting on the plum. Wing-flicking behaviour by peacocks is effective when thwarting attacks from birds, but was fatal when practised against hornets. A hypothesis for the evolution of intimidating eyespots on butterfly wings is advanced, suggesting that it is preceded by, and associated with, wing-flicking behaviour which in turn is associated with fruit- or sap-feeding.

C. Wiklund, Department of Zoology, Stockholm University, SE-10691 Stockholm, Sweden; Email: christer.wiklund@zoologi.su.se

Received 07 January 2004, accepted 05 January 2005

\section{Introduction}

Slobodkin (1968) once described evolution as a zero sum game, or an existential poker game in which the only reward is the player's persistence in the game. Evolutionary history demonstrates that no strategy of survival can guarantee eternal success or infinite persistence, although some options for life eternal appear, in a sense, better than others. For instance, when it comes to defense against predators among potential prey with a multitude of enemies, acquiring bodily noxiousness and following this up with warning coloration to keep potential predators at bay for their own good would seem a successful strategy. As a case in point the monarch butterfly, Danaus plexippus (L.), could serve as an example with the larvae sequestering cardenolides through feeding on herbs in the Asclepiadaceae, which renders them poisonous and unpalatable to most predators (Brower et al. 1967). Indeed, the monarchs in North America have attained very high population numbers, and spend the winter hibernating in the highlands of Mexico. Here, monarchs assemble in the canopy of three conifer species and number up to15 million individuals, and were long thought to be immune to predation (Brower et al. 1977). However, recent research has shown that three birds, Scott's oriole, Icterus parisorum Bonaparte, the black-backed oriole, Icterus abeillei(Lesson), and the black-headed grosbeak, Pheucticus melanocephalus (Swainson), have evolved adaptations to make use of monarchs as food and take a heavy toll on hibernating monarchs - first assessing the poisonousness of individual monarchs by tasting their wings, and then 
consuming less poisonous individuals (Calvert et al. 1979, Fink \& Brower 1981). Hence, in evolution there is no safe haven for potential prey, because of the variety of potential predators out there.

Another anti-predation device which appears to be successful, is furnished by the eyespots on the dorsal wing surface of some nymphalid butterflies such as the peacock Inachis io (L.). Although peacocks are perfectly palatable to many predators their large eyespots are intimidating to small passerines and experiments have demonstrated that yellowhammers Emberiza citrinella L., and blue tits Parus caeruleus L., cannot muster the courage necessary to kill and eat peacocks (Blest 1957, Vallin et al. 2005). When attacked by a bird the peacock performs a special wing-flicking behaviour described by Blest (1957) as follows:

"A repeated sequence of movements whereby the wings are depressed, exposing the forewing eyespots, and the forewings themselves strongly protracted, revealing those of the hind wings. The latter movement is accompanied by a hissing noise, produced by a specialisation of the structure of the basal thirds of the anal veins of the forewings and the costal veins of the hind wings which are rubbed together (Swinton 1876)."

The peacocks not only have large eyespots as a defense against visual predators and a stridulatory sound defence in the hearing range of human beings, but also produce an ultrasonic click which occurs as the wings are flicked open. This ultrasonic click is generated by a stiff portion of the wing membrane between the costal and subcostal veins near the base of the forewing, and appears to be an effective means of protection against bats (Møhl \& Miller 1976). This multimodal defense may be effective against different kinds of vertebrate predators, but it is conceivable that insect predators such as hornets Vespa crabro L. are less likely to be impressed with these defenses. In fact some anti-predation defense behaviours which are effective against vertebrate predators may be counterproductive when adopted against invertebrtae predators, and in this paper I shall describe observations to this effect when relating a week's observation on hornets preying upon peacocks when feeding on fermenting plums.

\section{Material and methods}

The observations were made near Ängelholm in the county of Scania in southern Sweden during four sunny days, between 6-9 August 2002, for a total of ca. 12 hours, and relate to insect interactions on, and in the immediate vicinity of, a plum tree, Prunus domestica, variety “opal”. In 2002, the tree had produced several hundred fruits and in the beginning of the observation period between 100-150 plums were lying on the ground underneath the tree, and about 100 plums were still hanging on the tree. Regardless of whether the plums were still on the tree or lying on the ground, they were all in a state of fermentation during the week of observation and the majority of plums had punctured skins from blue tits which had been eagerly pecking on the fruits the preceding week. The fermenting fruits were fed upon by a variety of insects including three species of butterflies, peacocks, Inachis io, red admirals $\mathrm{Va}$ nessa atalanta (L.), and graylings Hipparchia semele (L.), two species of flies, greenbottles $L u$ cilia caesar (L.), and fleshflies Sarcophaga carnaria L., as well as yellowjackets Vespula germanica (Fabricius). (I did not collect any voucher specimens and so the identification of the two fly species is somewhat uncertain.) In addition to these insects that were feeding on the juices of the fermenting plums, the area was also visited by hornets Vespa crabro that never seemed to be attracted to the fruit but rather attacked the insects feeding on the fruit.

\section{Results}

The number of insects feeding on the plums varied both during the course of a day and over the four-day observation period, but a one-minute count at noon on 7 August revealed 21 peacocks, 4 red admirals, one grayling, ca. 30 greenbottles, ca. 10 fleshflies, and ca. 20 yellowjackets. Focusing on the peacocks, a single butterfly could sit with its proboscis inserted into a hole in the rotting fruit for 15 minutes or more, unless disturbed. When feeding, the peacocks would always sit with their wings folded, hence revealing only the blackish barklike underside of their wings. Quite often a foraging butterfly would, 
Fig. 1. A hornet Vespa crabro attacking a peacock butterfly on the ground. The two forewings have already been chewed off and are lying on the ground, and the hornet is just beginning to chew off the first of the hindwings.

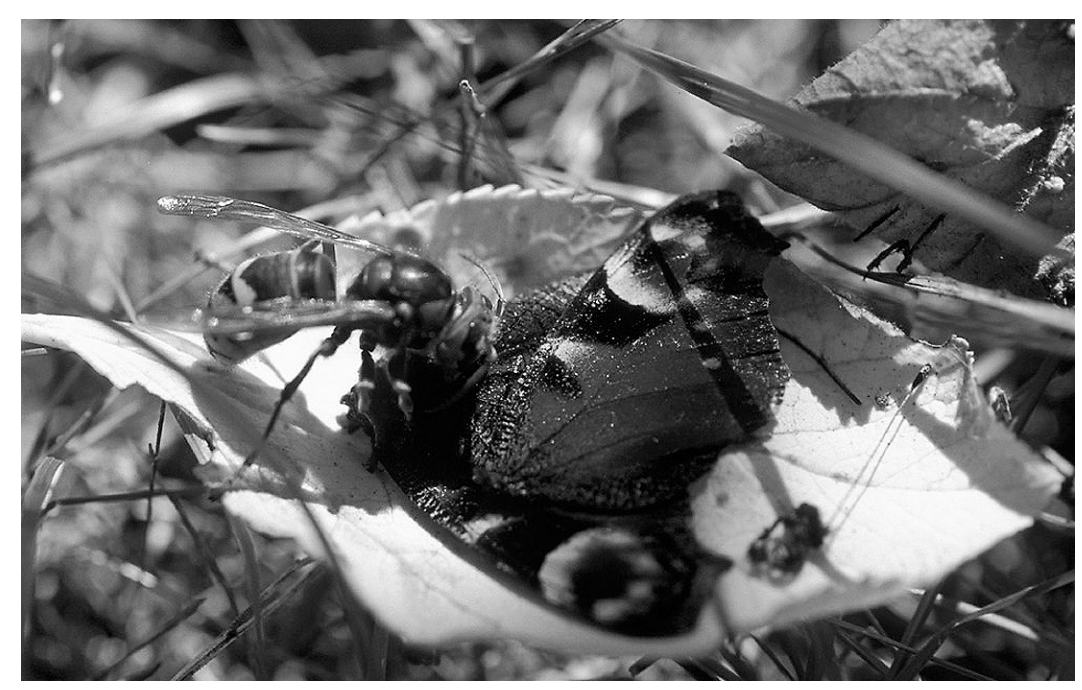

however, be disturbed by another insect aiming at joining in on the feast; this could be either another peacock, a red admiral, a greenbottle, a fleshfly, or a yellowjacket. Irrespective of whether the approaching insect was another butterfly, a fly or a wasp, the feeding peacock would invariably respond by flicking its wings open and thereafter closing, this opening and closing of the wings being repeated a couple of times in rapid succession. In case the approaching insect immediately flew away, the feeding peacock would immediately resume its position with the wings closed, but if the approaching insect was more insistent and continued to try to land on the already occupied plum, the feeding peacock would remain in position with the wings open for as long as the insistent intruder did not back off, giving the appearance akin to that of a vulture sitting on a carcass with its large wings open in the hope of making the food source inaccessible to others. More often than not, the peacock would be successful in preventing the other insect to land on the occupied plum, but sometimes a newcomer, who would not accept "no" for an answer, would join in, and occasionally two or three butterflies, or one butterfly and one or two flies, could feed simultaneously on the same fermenting plum.

My interest in the insect life underneath the plum tree was aroused by the observation of a peacock behaving in an awkward manner, opening and closing its wings, in the grass underneath the plum tree on 6 August. Closer inspection re- vealed that the strangely behaving peacock was being attacked by a hornet which was sitting on the battling butterfly. Within 15 seconds, the hornet started chewing off the wings of the butterfly, one by one, and thereafter severing the abdomen from rest of the body, eventually flying off with the thorax of the butterfly firmly held between its legs. After this predatory event I spent another 12 hours over the next three days watching for hornet attacks on plum-feeding insects and observed a little over a hundred attacks on peacock butterflies out of which four ended fatally for the butterfly.

Two of the four successful hornet attacks were made on peacocks feeding on plums lying on the ground among relatively tall grass which prevented free escape on the part of the butterfly, and another two on peacocks feeding on plums in the canopy where the multitude of branches prevented free escape of the butterfly. The procedure of a successful attack was largely identical in all of the four cases; the hornet would approach a butterfly which was sitting with its wings closed, but upon being approached the peacock would flick its wings open, whereafter the hornet descended on the dorsal part of the butterfly and attached its tarsi on the thorax of the butterfly. After a brief struggle during which the hornet appeared to sting the butterfly - this struggle, however, was hard to $100 \%$ confirm because of the flurried action, but evidently the hornet bent its abdomen as if intending to sting the butterfly - the hornet pro- 


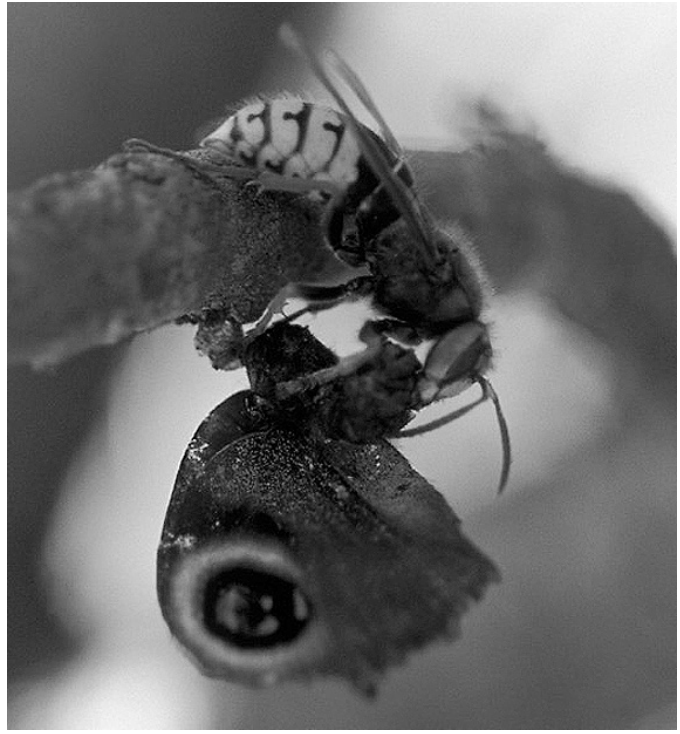

Fig. 2. A hornet Vespa crabro attacking a peacock butterfly among the branches of a plum tree. The forewings and one hindwing have already been cut off and the hornet is in the process of handling the butterfly before chewing off the second hindwing.

ceeded to chew off the four wings of the butterfly one by one, and then cutting of the abdomen before flying away with the head and thorax (Figs. $1-2)$.

Over one hundred hornet attacks on peacocks feeding on plums in shortcut vegetation were unsuccessful, and it seemed that the hornet could not get a grip on the butterfly when the peacock kept its wings closed. Typically hornets would fly much like a bomber plane in a heavy straight route from plum to plum and approximately one third of the peacocks would remain sitting with wings closed, whereas another two thirds flew away when attacked. The hornet would usually try to follow the butterflies that took flight, but always gave up after 5-10 seconds' pursuit. These chases were invariably unsuccessful as a result of the hornet being at such a disadvantage when it came both to speed and maneuverability. In addition to the four peacocks that were directly observed being preyed upon, hornets killed another 12 peacocks, as judged by cut-off wings found in the evenings between 6-9 August; in all, 11 right fore wings, 7 left fore wings, 12 right hind wings and 7 left hind wings from peacocks were found in the vegetation underneath the plum tree. It ap- peared that the hunting success of hornets decreased with time over the four-day observation period: all of the four successful attacks occurred during the first two days of observation, and the remains of at least eight peacocks were found underneath the tree after two days of observation, compared to an additional minimum of four peacocks being found after the last two days. This decrease in hunting success could be due either to surviving peacocks learning how to cope with attacks from hornets, the bomber-like sound that always preceded the attcks could conceivably be used as a cue to imminent attack, to decreased hunting efficiency associated with hornet aging as the season approached its termination, or both.

Although the hornets would fly in a straight trajectory from plum to plum, I witnessed two attacks on loose peacock hind wings (from previously killed butterflies) that were lying in the grass with the eyespot exposed. This indicates not only that the hornets were not intimidated by the large eyespots, but rather used them as a search image for finding peacocks to attack. However, it was not uncommon to see hornets fly towards plums without insects on them, and they also caught other insects feeding on the plums: during the four day observation period I witnessed hornets killing two greenbottles and one fleshfly. In addition, I also found one cut off right forewing from a red admiral lying on the ground underneath the tree on 7 August, which demonstrates that hornets did not refrain from attacking other butterflies beside peacocks.

It was difficult to assess the exact number of hornets hunting on the premises, but there was a minimum of two individuals. On 9 August I observed a hornet behaving strangely, sitting on a branch on the plum tree, and after a while a second hornet came flying against it starting to investigate it, but flying away after a few seconds. In the evening I found one hornet lying dead on the ground underneth the branch where it was erlier observed. No hornets were observed after 10 August.

\section{Discussion}

Although the relative rarity of hornets in the Nordic countries makes it unlikely that they have 
a major impact, the observations reported here suggest that hornets may be relatively important predators on peacock butterflies on a local scale. Regardless, the predation pressure from hornets illustrates a fundamental problem in decisionmaking on the part of potential prey $t$ that have variety of potential attackers. Wing-flicking may be an effective defense against small passerines and bats, as evidenced by experiments by Blest (1957) and Møhl and Miller (1976), but appears to be not only ineffective but counterproductively fatal as a defense against hornets which appeared incapable of capturing peacocks with closed wings, only being able to kill peacocks that held their wings open.

Although the developmental aspects of eyespot formation in butterflies has attracted great attention in recent years (Nijhout 1991; Brakefield et al. 1996; Brakefield \& French 1999), I am not aware of a single hypothesis advanced to explain the ecological conditions which are instrumental to the evolution of complex intimidating eyespots. Work by Young $(1979,1980)$ on Neotropical Morpho butterflies suggests that those species with well-developed, ventral eyespot rings feed on rotting fruit on the ground and are thus exposed to a particular type of high intensity predation. Species that seldom rest on the ground have much smaller eyespots, presumably because larger ones would disrupt their crypsis when at rest among foliage. However, this hypothesis relates to enlarged eyespots formed from border ocelli which constitute an integrated part of the nymphalid butterfly "ground plan" (Schwantwitsch 1924; Süffert 1927; Nijhout 1992) and so requiring no particular explanation for their evolution, only for their enlargement. Moreover, the enlarged eyespots are exposed on the ventral wing surface, and are assumed to have a deflective rather than an intimidating function as evidenced by beakmarks on the wings of these "eyespot butterflies" [Young (1979, 1980); see also Ruxton et al. (2004) for a recent review of the evidence of the functional significance of marginal eyespots on butterfly wings].

In the following I will advance a hypothesis for the evolution of complex anti-predator intimidating eyespots on the dorsal surface of the wings, based on the idea that wing-flicking behaviour is a prerequisite. Most palatable butter- flies rely for their survival on not being discovered by predators, and so are as a rule cryptically colored on the ventral surface of the wings, i.e. the surface that is exposed when the butterfly is at rest. For crypsis to be effective it must be combined with motionlessness on the part of the butterfly, because movement greatly increases the probability that the butterfly will be discovered by a predator. Comma butterflies Polygonia c-album (L.) exhibit this motionless "behaviour" and predation experiments using great tits Parus major L. as predators in an experimental set-up revealed that comma butterflies do not ever move even as the observant birds bends forwards and catches it in its beak (Wiklund \& Tullberg 2003). So, the problem is to understand how wing-flicking behaviour has evolved, because it appears to be a necessary prerequisite for the evolution of intimidating patterns exhibited on the dorsal side of the wings; if the dorsal part is not ever exposed, there is little incentive for evolution of specific colour patterns that serve a predator defense function.

In a general sense, wing-flicking is exhibited by most species of butterflies when they are active and it is generally practiced when a butterfly is sitting and is approached by another flying animal whose approach is not regarded as threatening enough to release flight behaviour. So, male butterflies, when approached by another conspecific male, often react by opening and closing the wings a couple of times in rapid succession, thereby making it impossible for the approaching butterfly to alight. Likewise, wing-flicking can be exhibited by butterflies that are approached when sitting on a flower nectaring. However, extended wing-flicking, and the use of keeping the wings open as a means to prevent competing foragers from being able to alight, should be most prominent among species feeding on a rich but spatially limited food source, such as a small fruit or sap from a tree. Once wing-flicking behaviour has evolved it opens the possibility for the evolution of intimidating wing patterns on the dorsal wing surface. Insofar as the habit of extended wingflicking is instrumental to the opportunity for intimidating eyespots to evolve, it should expected that large eyespots should be more prevalent among fruit- and sap-feeding butterflies compared to flower-visiting species. 
An additional factor that could favour the evolution of effective anti-predator adaptations among fruit- and sap-feeding butterflies is the richness of the food source which appears to make the foraging butterflies should be unwilling to abandon it, which as a secondary consequence could make them more prone to be targeted and overtaken by predators. Young (1979, 1980), when drawing attention to the fact that the Morpho Fabricius species with the most well-developed eyespots typically fed on fermenting fruits on the ground, suggested that ground-feeding per se made them more exposed to high intensity predation, thereby "necessitating" effective anti-predation coloration. On top of this, Young suggested that intoxication brought on by the consumption of fermenting juice could impair escape ability, and so add to the advantage of an effective anti-predator coloration. Another aspect of butterfly feeding on fermenting fruit is that it is a rich and concentrated source of food which should not be voluntarily abandoned unless "necessary", and so it seems likely that the decision to take flight in the face of an approaching flying object should be more time-consuming among fruitand sap-feeding species, and so should further implement the advantage of effective anti-predator coloration.

As mentioned above the evolution and development of eyespot patterns in butterflies has aroused substantial interest in recent years (Nijhout 1991, Brakefield et al. 1996, Brakefield $\&$ French 1999), but virtually all of the research effort in the field has been devoted to the analysis of the development of the "border ocelli" (sensu Nijhout 1991) and little effort has been aimed at understanding the evolution and development of large complex eyespots such as that of the peacock, which are fundamentally different from those of eyespots derived from enlarged border ocelli. Nylin (unpubl. data) has estimated that large eyespots have evolved at least 30 times in butterflies, but again the overwhelming majority of these are derived from border ocelli. Hence, the notion that the evolution of large eyespots that are "created de novo" (in the sense that they are not derived from border ocelli) represents a complex adaptation that should be definition be not so easily achieved, appears borne out by its apparent rarity. It is noteworthy that recent phylogenetic research indicates that peacocks and small tortoiseshells are sister taxa, and that the Inachis/ Aglais clade is the sister clade to the Polygonial Nymphalis clade (Wahlberg \& Nylin 2003). This means that the evolution of eyespots must have occurred after the separation of Inachis from Aglais and suggests strong selection for the perfection of the large intimidating eyespots on the wings of the peacocks.

Acknowledgements. I thank Birgitta Tullberg and Sören Nylin for comments on the manuscript. This work was funded by a grant from the Swedish Research Council.

\section{References}

Blest, A. D. 1957: The function of eyespot patterns in the Lepidoptera. - Behaviour 11: 209-256.

Brakefield, P. M., Gates, J., Keys, D., Kesbeke, F., Wijngaarden, P. J., Monteiro, A., French, V. \& Carroll, S.B. 1996: Development, Plasticity and evolution of butterfly eyespot patterns. - Nature 384: 236-242.

Brakefield, P. M. \& French, V. 1999: Butterfly wings: the evolution of development of colour patterns. Bioessays 21: 391-401

Brower, L. P., Brower, J. V. Z. \& Corvino, J. M. 1967: Plant poisons in a terrestrial food chain. - Proc. Nat. Acad. Sci. 557: 893-898.

Brower, L. P., Calvert, L. P., Hedrick, L. E. \& Christian, J. 1977: Biological observations on an overwintering colony of monarch butterflies in Mexico. - J. Lepid. Soc. 31: 232-242.

Calvert, W. H., Hedrick, L. E. \& Brower, L. P. 1979: Mortality of the monarch butterfly (Danaus plexippus): Avian predation at five overwintering sites in Mexico. - Science 204: 847-851.

Fink, L. \& Brower, L. P. 1981: Birds can overcome the cardenolide defence of monarch butterflies in Mexico. - Nature 291: 67-70.

Møhl, B. \& Miller, L. E. 1976: Ultrasonic clicks producwed by the peacock butterfly: a possible bat-repellent mechanism. - J. Exp. Biol. 64: 639-644.

Nijhout, H. F. 1992: The development and evolution of butterfly wing patterns. - Smithsonian Institution Press, Washington. 297 pp.

Schwanwitsch, B. N. 1924: On the groundplan of wingpattern in nymphalids and certain other families of rhopalocerous Lepidoptera. - Proc. R. Soc. Lond. Ser. B 34: 509-528.

Slobodkin, L. B. 1968: Toward a predictive theory of evolution. - In: Lewontin, R. (ed.), Population biology and evolution: 187-205. University of Syracuse Press, Syracuse.

Ruxton, G. D., Sherratt, T. N. \& Speed, M. P. 2004: Avoiding attack: The evolutionary ecology of crypsis, warning signals and mimicry. - Oxford University Press, Oxford. 
Süffert, F. 1927: Zur Vergleichende Analyse der Schmetterlingszeichnung. - Biol. Zentralbl. 47: 385-413.

Swinton, A. H. 1876: On stridulation in the genus Vanessa. — Ent. Month. Mag. 13: 169-172.

Vallin, A., Jakobsson, S., Lind, J. \& Wiklund, C. 2005: Prey survival by predator intimidation - an experimental study of peacock butterfly defence against blue tits. - Proc. Roy. Soc. Lond. B (in press).

Wahlberg, N. \& Nylin, S. 2003: Morphology versus molecules: resolution of the positions of Nymphalis, Polygonia and related genera (Lepidoptera: Nympha- lidae). - Cladistics 19: 213-223.

Wiklund, C. \& Tullberg, B. 2003: Seasonal polyphenism and leaf mimicry in the comma butterfly. - Anim. Behav. 68: 621-627.

Young, A. M. 1979: The evolution of eyespots in tropical butterflies in response to feeding on rotting fruit: an hypothesis. - J. New York Entomol. Soc. 87: 66-77.

Young, A. M. 1980: The interaction of predators and "eyespot butterflies" feeding on rotting fruits and soupy fungi in tropical forests. - Entom. Rec. J. Var. 92: 63-69. 